This item was submitted to Loughborough's Research Repository by the author.

Items in Figshare are protected by copyright, with all rights reserved, unless otherwise indicated.

\title{
Gatekeepers' experiences of hiring a sport psychologist: a phenomenological study
}

PLEASE CITE THE PUBLISHED VERSION

https://doi.org/10.1080/10413200.2018.1484394

\section{PUBLISHER}

Taylor \& Francis (@ Association for Applied Sport Psychology)

\section{VERSION}

AM (Accepted Manuscript)

\section{PUBLISHER STATEMENT}

This is an Accepted Manuscript of an article published by Taylor \& Francis in Journal of Applied Sport Psychology on 17 September 2018, available online:

http://www.tandfonline.com/10.1080/10413200.2018.1484394.

\section{LICENCE}

CC BY-NC-ND 4.0

\section{REPOSITORY RECORD}

Woolway, Toby H., and Chris Harwood. 2019. "Gatekeepers' Experiences of Hiring a Sport Psychologist: A Phenomenological Study”. figshare. https://hdl.handle.net/2134/35363. 
1

2

3

4

5

6

7

8

9

10

11

12

14

15

16

17

18

19

20

21 Keywords: gatekeepers; gaining entry; applied practice; interpretative phenomenological

\section{Abstract}

Within applied sport psychology, the process of gaining entry, specifically the employment interview, has received little attention relative to other stages of practice. This study, guided by an interpretative phenomenological approach, aimed to understand the experiences of gatekeepers to practice within United Kingdom elite sport who have been directly involved in the hiring of sport psychologists. Semi-structured interviews with seven participants were transcribed verbatim and analysed using interpretative phenomenological analysis. Four essences emerged: consultant affability, consultant confidence versus arrogance, consultant collaboration, and presentation of consultant competency. These findings highlight the importance of developing interpersonal skills, interview technique, and self-promotion skills in sport psychology practitioners. In addition, a number of features specific to the sport psychology employment interview are discussed. analysis 
Sport can have a profound impact on individuals, communities and wider society

24 (Sport England, 2015) and in an environment driven by results, whether it be at a club,

collegiate or professional level, the "bottom line" for most organizations is winning

(Wrisberg, Withycombe, Simpson, Loberg, \& Reed, 2012). With the financial consequences

27

28

of winning and losing, those involved in sport have been faced with the question of how to improve their rates of success (Humara, 2000). Hence, it is not uncommon for an array of sport science support personnel to be recruited at all levels of competition to help manage the physical demands of practices and competition (Wrisberg et al., 2012). However, a hesitancy to seek the services of a sport psychology consultant (SPC) is still prevalent despite a shared acknowledgement of the importance of sport psychology for success in a wide-range of sporting environments from Olympic Games (Hodge, 2010), to Academy Soccer (Johnson, Andersson, \& Fallby, 2011).

Wrisberg and colleagues (2012) suggest that to propel and develop the field of applied sport psychology, lessons should be learned from the sudden change in perceptions of strength and conditioning in the 1970s. At that time, athletic directors were sceptical of the potential benefits of strength and conditioning, even presuming that its practice impaired performance (Lukacs, 2010). Within a decade practically every NCAA Division-I athletic director had hired strength and conditioning coaches, possibly due to a better awareness about the potential benefits and services that strength and conditioning provided (Wrisberg et al., 2012). In addition, both program evaluation and professional accountability require greater attention (Gould, Murphy, Tammen, \& May, 1991). In addressing this concern, Sharp and Hodge (2014) stated that "substantial progress has been made in identifying the characteristics and qualities necessary for effective sport psychology consulting” (p. 92). This field of research has found many characteristics to be important for consultant effectiveness that include (but are not limited to) being; knowledgeable about sport psychology, honest, 
48

trustworthy (Anderson, Miles, Robinson, \& Mahoney, 2004), and able to build a connection and professional consulting relationship with the athlete (Sharp \& Hodge, 2011). However, Andersen (2000) suggested that before we ask what happens when athlete meets sport psychologist, "we need to look at the situations, environments, and processes that help bring a client and a sport psychologist together for the first time” (p. 3).

To ensure the maximum uptake of the services that consultants provide, it is critical to understand the factors that influence a consultant "gaining entry" to an organisation/team. Gaining entry is the stage of consultancy that begins with initial contact between two parties through to the formal agreement/and or the signing of formal documents between the sport psychologist and the future working party (Coumbe-Lilley, 2011). Without successful negotiation through this stage, practitioners may risk falling at the first consultancy hurdle. The specifics of gaining entry, as the first stage of consultation process models (e.g., Sport Psychology Service Delivery Heuristic; Poczwardowski, Sherman, \& Ravizza, 2004) are often under-discussed due to the generic nature of exploring the consultation process. However, contrasting lines of research (e.g., consultant characteristics, barriers to entry) in the field of professional practice often converge when studying the process of gaining entry to practice. The literature on consultants' characteristics, originally stemming from research in allied professions such as counsellors, physicians, and therapists, has received the most research interest and attention (Dorn, 1984; Hash, Munna, Vogel, \& Bason, 2003; Lewis \& Walsh, 1978; Woolway \& Harwood, 2015). This field of study explores the influence of the practitioners' traits, appearance, and background on potential consumers’ perceptions of effectiveness and preferences for future consultation. When reviewing this literature, the most preferred sport psychologist was of the same age and race to potential consumers, and possessed a high athletic background, interpersonal skills, and sport specific knowledge (see Lubker, Visek, Geer, \& Watson, 2008; Woolway \& Harwood, 2015). They were female, 
73 athletically built, physically active, had experience working with diverse populations, and

74 possessed either an advanced degree or certification (cf. Lubker, Visek, Watson, \&

75 Sungpurwalla, 2012).

Barriers to entry, those factors that may act as blocking agents to the successful entry

77 of a practitioner, have also garnered an increasing amount of interest within a variety of

78 settings. Both internal (e.g., finance and time) and external (e.g., SPC integration and the

79

80

81

82

83

84

85

86

87

88

89

90

91

92

93

94

95

96

97 negative perceptions of coaches) barriers have been found to hold a significant influence over individuals' likelihood to seek the services of an SPC (Pain \& Harwood, 2004). Despite these areas of study being important to the understanding of gaining entry, it is beyond the scope of this paper to provide an in-depth discussion and critique of these fields (see Johnson, Andersson, \& Fallby, 2011; Woolway \& Harwood, 2015). However, one aspect of the gaining entry process that appears to have been overlooked by sport psychology professional practice literature is that of the entry/employment interview. This encounter with an organisation's 'gatekeeper to sport psychology' is an interpersonal interaction that may influence the success or failure of consultancy before it has begun.

The employment interview is an assessment tool that can be manipulated to assess a range of constructs from declarative knowledge to individual experience (Huffcutt, 2011). As an interdisciplinary field, sport psychology should look beyond its boundaries to other fields (Poczwardowski, Sherman, \& Henschen, 1998). Within this area, the most closely allied research fields are occupational psychology and literature examining the selection of personnel. A focus of such psychological inquiry regarding the employment interview has been the many constructs that influence interviewer ratings of candidates (Higgins \& Judge, 2004). For example, within personnel selection, Huffcutt (2011) found that, job-related interview content (information pertaining directly to the requirements of the position), interviewee performance (the performance of the candidate), and personal/demographic 
98 characteristics (grouping features that may affect ratings) are major sources of employment

99 interview ratings. Interviewee performance constructs (e.g., impression management techniques) correlated more strongly with interview ratings than the two other constructs.

101 Additionally, within selection and assessment research, Peeters and Lievens (2006) found

102 that individuals can choose the impression management tactics that will have the greatest

103 impact on interviewer ratings. These findings, particularly those regarding impression management and interviewee performance highlight the importance of the individuals’ interpersonal skills in determining the outcome of an employment interview. This finding may be particularly important to the SPC whose success depends on building a rapport and

107 relationship with the client. Drawing upon research from differing professions can aid in our

108 understanding of this phenomenon, however a considerable amount of studies utilise a laboratory design (Huffcutt, 2011). This limitation highlights the need to extend research into the sport psychology domain, using methodology that examines the actual phenomenon of an

111 employment interview. Guest (1998) argued that a comprehensive and valid understanding of the

113 employment relationship is unlikely to develop until researchers begin to consider the 114 perceptions and reactions of both parties in the relationship, the organisation and the individual. The employment interview requires interaction between the sport psychologist

116 and the organisation's representing agent. In the microcosm of elite sport, it is the athletic

117 directors (Wilson, Gilbert, Gilbert, \& Sailor, 2009), administrators, coaches, team captains 118 (Sands, 2002), and organisational presidents (Wrisberg et al., 2012) that are at the helm due 119 to their control of budgets and key decisions. These 'gatekeepers' are those that control access to other group members, group activities, and sources of information (LeCompte \&

121 Schensul, 1999). Understanding how these individuals’ perceptions, preferences and beliefs 122 affect the provision of sport psychology consulting within athletic departments can provide 
123 useful information to organisations and individuals promoting applied sport psychology

124 (Wilson et al., 2009). Past research has examined gatekeepers’ and potential consumers

125 likelihood to seek the services of a sport psychologist, as an aspect of the gaining entry

126 process (Wilson et al., 2009; Woolway \& Harwood, 2015). Recent research suggested that

127 understanding the hiring experiences and decisions of individuals with direct organizational

128 responsibility for employing SPCs would provide clarity to previous findings from

129 prospective consumers (Thelwell, Wood, Harwood, Woolway, \& van Raalte, 2018). The

130 employment interview is an interpersonal phenomenon that has received little attention

131 within the applied sport psychology domain, which when examined can provide the insights

132 of those gatekeepers with direct responsibility for hiring SPCs.

133 The current research study aimed to explore the lived experiences of individuals who

134 have employed SPCs previously; specifically, those hired through employment interviews.

135 Additionally, it endeavoured to explore how these lived experiences have shaped their current

136 perceptions and future hiring beliefs. When conducting research into a novel topic, rich

137 detailed information is important to develop our understanding of the field. Since little is

138 known about the phenomenon of the SPC employment interview, and the current study

139 sought to explore the experiential data of participants, phenomenology was chosen as an

140 appropriate approach for collecting and interpreting descriptions of participants.

141 Interpretative Phenomenological Analysis (IPA) strives to understand individuals’ lived

142 experiences to describe what a phenomenon is like for them (Larkin, Watts, \& Clifton, 2006)

143 placing social interaction and the cultural context at the heart of the research endeavour

144 (Clarke \& Harwood, 2014). In addition, IPA “offers psychologists the opportunity to learn

145 from the insights of the experts” (Reid, Flowers, \& Larkin, 2005, p. 20). Subsequently, this

146 research aims to explore how gatekeeper experiences are shaped by the sport psychologist 
147 within the context of entry to practice interviews. Additionally, it endeavours to explore how

148 these lived experiences have shaped their current perceptions and future hiring beliefs.

\section{Methods}

150

151

152

153

154

155

156

157

158

159

160

161

162

163

164

165

166

167

168

169

170

171

\section{Methodology}

An interpretative phenomenological research design was utilised in this study; a branch of phenomenology which draws upon Husserl (1973) and involves detailed examination of the participant's personal experience (Smith \& Osborn, 2004). In addition, IPA emphasizes the active role of the researcher as their own conceptions are required to make sense of the other participants' personal worlds through a process of interpretative activity. Smith and Osborn (2004) propose that a two-stage interpretation process takes place, where participants are trying to make sense of their world whilst the researcher is trying to make sense of the participant's interpretations. IPA is particularly useful when investigating an area that is new or under-researched. Despite studies often mapping individuals’ experiences of a variety of conditions and interventions (Hamill, Carson, \& Dorahy, 2010, Rhodes \& Smith, 2010), there is a growing body of work that moves beyond describing episodic accounts of experience and further addresses the meanings held by professionals in their own lines of work (Arvinen-Barrow, Penny, Hemmings, \& Corr, 2010, Vachon, Fillion, Achille, Duval, \& Leung, 2011). It is important to note that IPA has received criticism for lacking agreement with any particular phenomenological school (Giorgi, 2011) and may be best described as phenomenologically inspired and interpretatively-focused (Miller, Cronin, \& Baker, 2015). Importantly, Brocki and Wearden (2006) state that IPA researchers with different interests may adopt different levels of interpretation in varying topics. Thus the role of the researcher's own position in the interpretation process and concerns regarding research credibility are addressed below.

\section{Participants}


IPA aims to gain a detailed and personalised understanding of each case resulting in many research studies having sample sizes of 10 or fewer (Caron, Bloom, Johnston, \&

174 Sabiston, 2013; Smith, 2016). In line with these IPA guidelines (Smith, Flowers, \& Larkin,

175 2009), seven gatekeepers of sport psychology were sampled utilising purposive homogenous

176 sampling through contacts made for the current study, contacts previously held by the second

177 author, and peer recommendations. Participants were gatekeepers to sport psychology within

178 United Kingdom elite sport organisations who had professional experience in gatekeeping

179 roles ranging between 3 and 27 years. All participants had been directly responsible for hiring

180 at least two SPCs, however some of the participants could not accurately account for how

181 many SPCs they had historically hired on service-based contracts. Participant experiences of

182 the employment interview process ranged from one interaction with the SPC to four separate 183 interactions before the employment decision.

Six male and one female gatekeepers aged between 34 and 57 (M=41.2) participated in the current study. The participants’ roles in their organisations were: Head of Performance Support, Head of Sport Science \& Medicine, Performance Director, Paralympic Lead, Head 187 of Sport Science, Senior Psychologist, and Academy Director. Four sports (Martial arts, rugby, cricket, and tennis) were represented along with a UK based sport science services organisation.

In accordance with ethical requirements, participants are identified by culturally

191 appropriate pseudonyms.

\section{Data Collection}

Following institutional ethical board approval, potential participants were contacted

194 based upon their current roles within professional organizations. Selection was guided by an

195 individuals' extensive involvement in the recruitment and hiring of sport psychologists. Male 196 and female participants from both private and public-sector organisations, representing four 
197 different sports were recruited. This allowed for both experiences that are common to the sample, and those that are unique to individuals to be presented (Clarke \& Harwood, 2014). Data were collected using semi-structured phenomenological interviews between the lead investigator and individual participants. The interview guide was created using guidelines to conducting IPA studies (Smith, 2016; Smith et al., 2009). Questions were designed to gather information on what the participants experienced and how this influenced their experience. The interview schedule was designed with a focus on open questions, to allow the participants to express their experiences as wholly as possible. As such it served merely as a stimulus to aid discussion rather than being rigidly used (Smith, 2016). A summarised schedule of questions was sent to the participants at least three days prior to the interview to aid them in providing detail that might not have been revealed with the use of unseen questions, and to facilitate their own reflection on pertinent experiences (Hays, Maynard, Thomas, \& Bawden, 2007). The schedule itself was guided by questions such as:

1. When I talk about hiring an SPC, what does that mean to you?

2. Can you tell me about your experiences when hiring sport psychologists? participants were only returned to the interview schedule when the interviewer deemed that a recount of experience had ended. Additional questions were designed to establish how the gatekeeper experiences affected their current perceptions and views of sport psychology, and their future hiring beliefs, such as:

1. Based on your past experiences would you hire an SPC again?

2. Do you think your past experiences have changed the way you would hire a sport psychologist in the future? 
1. Is there anything else that you would like to talk about that we haven't covered?

2. Do you feel that you had a chance to share everything you wanted to?

A pilot interview was held to trial the questions and interview technique. Following

the pilot interview, several additional questions were formulated to provide a deeper

understanding of gatekeepers’ perceptions and experiences. A question regarding participants' perceptions of sport psychology prior to their first encounter was added to aid in developing an understanding of potential influences on interactions with SPCs. In addition, further validation was added to increase the participants' chance to share their experiences. Each interview was audio recorded and transcribed verbatim. The mean interview duration was 45 minutes $($ Range $=36$ to 57 minutes, $\mathrm{SD}=7.16$ ). To ensure confidentiality for participants, data were anonymised at transcription and participants were assigned pseudonyms.

\section{Data Analysis}

IPA is a flexible perspective used in the analysis of qualitative data that involves a close examination of each case (Caron et al., 2013; Smith, 2016). Despite Smith (2016) suggesting that "there is not a single right way to do IPA analysis" (p. 222) the general guidelines proposed by Smith and colleagues (2009) were adopted for this study. During this process, the first author engaged with the concepts of bracketing and a search for essences.

The process of bracketing requires the researcher to explicitly identify their own preconceptions relating to the topic (Tamminen, Holt, \& Neely, 2013). However, it has been suggested an impossibility to completely bracket one’s predisposed biases (Allen-Collinson, 2009). In the current study, the first author identified their assumptions informed by prior research by listing any preconceptions about the influences on perceptions and preferences for sport psychologists. The first author had no experience of hiring SPCs, therefore the author's understanding and preconceptions of experiences may have been limited. However, 
247 it should be acknowledged that to some extent, prior understanding may still have informed analysis. This setting aside of preconceptions attempts to avoid imposing these biases formed through personal experiences (Sanders \& Winter, 2016). Consistent with IPA guidelines, each transcript was analysed as a case in its own right

251 (Smith, 2016). Hence the first four stages of analysis were conducted on one transcript before 252 attending to the next. Transcripts were read and re-read to achieve a sense of familiarity with each participant’s experience (Stage 1). The data was next attended to with the aim of identifying themes by making comments in the margin of the page that was descriptive, linguistic, or conceptual in nature (Stage 2). A return to the beginning of the transcript was made to identify and label essences in the opposing margin to the one used earlier, before 257 connections between the themes were sought (Stage 3). A table of 'essences' was then 258 produced (Stage 4). This method of analysis was then repeated for each transcript. This repeated process followed by a comparison of individual data to others, allowed the researchers to discover the universals underlying the inter-subjectively experienced

261 phenomenon (Crotty, 1998; Stage 5). Analysis was initially conducted by the first author, 262 followed by both authors engaging in discussions to review the analytic approach (Sanders \& 263 Winter, 2016). The final step of IPA was writing; translating essences into a coherent account 264 (Smith et al., 2009; Stage 6).

A relativist approach was applied to guide the judging of quality in the current research (Smith \& McGannon, 2017). This approach does not utilise a set of universal criteria 267 that "are fixed, rigid, or predetermined before the study" (Smith \& McGannon, 2017; p. 16), 268 but uses a list of criteria that can be added to, subtracted from and modified. This study provides a substantive contribution to this field as the first qualitative study to offer an insight

270 into the experiences of those directly responsible for the hiring of SPCs. In addition, the 271 impact of the study is evident in the generation of further questions regarding the SPC 
272 influence on this phenomenon, and how this can be altered. The width of data is evident

273 through the numerous quotations provided to illustrate each interpretation, and the different

274 manifestations of each essence experienced by participants. Furthermore, the study displays

275 coherence in the presentation of those essences which were analogous to participants in order

276 to provide a meaningful picture of the employment interview phenomenon.

277 Smith and McGannon (2017) additionally suggested that the notion of critical friends,

278 to encourage reflection and provide alternative interpretations and perspectives should be

279 utilised. In line with this, the second author acted as a critical friend in reviewing the codes

280 and respective quotes interpreted by the first author.

281

\section{Findings}

282

The gatekeepers discussed various experiences of hiring SPCs that shared common

characteristics, which we have labelled consultant affability, consultant confidence versus

284

arrogance, consultant collaboration, and consultant competency. Despite all seven

285

participants' descriptions informing the findings, and detailed examples are provided for each

286

essence of their shared experiences, manifestations of these superordinate constructs were

287 aligned to different lower-order themes through the participants' experiences. These

emergent themes are therefore described in relation to these gatekeepers' experiences.

Consultant Affability: 'I needed an affability, an ability to relate'

We interpreted participants' descriptions of a sense of closeness, developing a

291 connection, and fitting in as being related to the consultant's affable nature. Despite the level

292 of affability varying across gatekeeper experiences, it was highlighted as a key factor in their

293 decision either to hire or not to hire. Andrew and Brian felt they experienced a sense of

294 closeness or a close relationship developing, however they initially could not offer an

295 explanation for this feeling: 
When he left we all felt like he was the right person; he left us with such a good impression about himself. He instantly struck up a relationship with the two coaches in the room and the interview ended up just being a conversation about [the sport] for large parts, but he just left us feeling that sense of 'we want this guy in our club' Andrew

I got on with him, which helps, he listened to what I wanted, um and I felt comfortable that he would be, he would be able to connect with the players I had in the academy - Brian For Brian, it appeared to be particularly difficult to "put [his] finger on” what created this feeling of potential connection and getting on with the SPC. Despite discussing that he “just felt a sense”, Andrew suggested that being able to instantly develop a relationship, and leading the interview into a more informal conversation resulted in positive reflections on this

SPC. Although not explicitly stated, Andrew and Brian seem to suggest that this initial connection was guided by the SPCs interpersonal skills. Hence, it was not surprising that some features commonly associated with interpersonal skills were explicitly detailed by two participants:

Their ability to immediately build rapport with our coaches and athletes was important too, so we would have some of them either in the interview or around the environment and how they handled that sort of situation - Matt Robert For Robert and Matt, this building of rapport, trust, and respect positively influenced 319 their perceptions of a SPC and whilst established during early interactions, appeared to 320 influence communication for the duration of the interview process. While reflecting on one 
321 encounter with a SPC, James' tone of voice suggested an enduring positive memory that "he had a personality [we] could get on with, they were positive and boosting to the whole environment”. For one of the participants, discussions turned to interactions with consultants who did not appear to possess the necessary interpersonal skills: They've come in one by one and it's been obvious within five minutes that they are not suitable for the role and those days are long days because you're interviewing eight or nine people and if we'd of had an opportunity to converse with them previously they wouldn't have been shortlisted...um it's a cutthroat world and [we] will know immediately as to whether that person has the personality and the social skills to be able to operate in that environment - Sarah For Sarah, this lack of "personality and social skills" led to a withdrawal from the consultant affability, and the enduring effects of these perceptions on hiring decisions. This desire for an interpersonal connection between the gatekeepers and SPC highlights the need for practitioners to possess the necessary skills to develop rapport, trust, respect, and a relationship with individuals at all levels and stages of consultation. Without this characteristic, it is apparent that the gatekeeper is likely to withdraw from interactions before the consultant can progress through other stages of the interview process. The

340 importance of consultant affability is perhaps best summarised by Stephen: Especially in sport psychology where you don't come with a gym, or you don't come with an ultrasound machine, you come with you, and your personality, and your rapport building skills are your gym essentially - Stephen

\section{Consultant Confidence versus Arrogance: 'they were too much into their ology'}


In addition to reflecting upon the consultant's affable nature, six of the participants

felt that their experiences of hiring were characterised by the consultants' attitude towards

psychology’s effectiveness and place within a multi-disciplinary team.

For Matt and Robert, the consultants exaggerated belief in the effectiveness of sport psychology appeared to lead to the gatekeepers’ withdrawal from further interaction with both the individual practitioner and, in the extreme, from the field as a whole: potentially lead to negative perceptions of the field to this day, identifying the durable nature 360 of perceptions of SPCs and the wider profession. For Matt, the affect displayed towards the SPC, led to dissipating interest in hiring the consultant. The differing extent of these responses may be explained by the gatekeepers’ prior experiences with SPCs. Robert was reflecting upon his first experience of hiring an SPC, likely making his knowledge of both the

364 field and such claims by the SPC less than that of Matt, who had previous experience of this 365 phenomenon. This experience may be the cause for Matt's withdrawal from the individual practitioner rather than a response of "despising the field” as a whole. 
Honesty. I think that's the biggest thing, we don't need to hear how you're going to save the world, we want to know honestly if you can do the job, and how you're going to do it - Andrew

Belief in what you do is obviously important, and we want someone to come in with a sense of they know what they're doing, and they will do the job, but sometimes that is taken to a different level, and it sounds like they are bragging about themselves and I guess the profession as a whole - Stephen

This highlights the need for SPCs to focus on providing consumers a truthful account

of the effectiveness and efficacy of their profession, without exaggerating potential benefits and time frames for these benefits.

Further to beliefs regarding the effectiveness of sport psychology, two participants discussed how SPCs portrayed perceptions of their position within multi-disciplinary sport science service provision:

[they] had their sense of importance way too high, when it works well we work a total interdisciplinary approach, which is a family feel, it's a corny word but it's actually the best sport teams are like families so nobody is more important than the others, everybody's helping other people whereas this particular sport psychologist was 'I want more psychology, psychology is the thing the [athletes] need', so there were a lot of friction points there - James When he said that psychology was key, that psychology was what was missing, if you're looking for a psych then you feel it's needed and that's what will make a difference, I mean he gave that impression of I want specified times for psych, and nothing else should infringe on that, no real flexibility there - Matt For Matt, the suggestion that sport psychology will induce a change in performance and a lack of flexibility of time and service provision, over complimentary services, 
interacted to develop a sense that sport psychology was the most important sport science service. James had wanted a SPC that fitted in with the "family feel" of the organisation and a belief that "psychology is the thing that is needed" did not match this want. Andrew shared an anecdote relating to his early experiences of a pre-existing SPC when entering a new organisation: well you need more psychologists you know this is literally what happened the guy said to me "I know you told me that we've not got any budget, but I went to see the CEO yesterday and asked him for more budget for psychology” - Andrew Andrew’s account, whilst discussing an already contracted SPC who he line managed, provides a warning to practitioners regarding their vision of sport psychology's position relative to the entire organisation and respect for their manager. Collectively, interpreted with 405 the recounted experiences of other gatekeepers this feature of experience highlights the need for SPCs to describe an honest and balanced belief in the field: I mean don’t get me wrong, I think everyone should believe in their own field, if you don't you shouldn't be doing it, but there is believing in it and there is thinking that you are God's gift to the club because of it, and that's not the impression we want to be given - Andrew

413 When consultants were appropriately confident in sport psychology, the participants' used 414 more language during their descriptions of experiences and ultimately lead to a more positive 415 perception of the consultant.

\section{Consultant Collaboration: 'I would go down a route where we find a common ground'}


419 discussed this need, however they diverged on what this agreement involved. We interpreted that gatekeepers' experiences were characterised by the consultant's ability to find both a common philosophy and a common plan.

423 philosophy of practice. However, the meaning of philosophy appeared to differ between 424 participants. Andrew discussed his experience of a consultant whose service focused on a humanistic approach, rather than solely on performance: [sport], which is obviously important, but then they went into other things, and how this could help them as people outside of it, that really struck me because it's not just about the sport for me, it's about producing more rounded people, and if they've got a greater understanding of psychology behind behaviour then they can take that into the work place and future life as well - Andrew

433 the practitioner's consultancy focus on both the psychological well-being and performance of 434 the athletes. In contrast, Robert appeared to reflect upon an instance of agreement on who the SPC was to work with:

So we wanted someone that could work with our elite players, and their coaches, and then the younger academy style guys, their coaches as well as their parents, so we wanted someone to cover all the bases, and there were a couple of people we interviewed that met those sorts of criteria - Robert This divergence in perceptions of philosophy indicates that both focus of service and

441 intended recipients are critical discussion points with gatekeepers. These features of the 442 consultant's philosophy proposed throughout the interview process appeared to be a major 
443 impact upon the participants' decision to hire or not to hire a SPC. However, it may not be 444 this simple for the consultant:

445

So yeah, we hired somebody who naturally, who believes that um the right, the most effective way to do it is with the coaches...but when it's the national governing body hiring then it's the responsibility of the psychologist to fit into the right way for that context - James James indicates the potential need for SPCs to be malleable concerning their philosophy of practice when attempting to gain entry with an elite organisation or National Governing Body. It was apparent from the discussion with James that this warning to practitioners was especially pertinent in relation to both the gatekeeper's experience with sport psychology and the practitioners experience. When the gatekeeper possesses experiences of employing SPCs, they appear more likely to have a developed perception of their desired philosophy:

So I, you know, I had the background in, in skill acquisition and sport psych which was useful for me to know what a program should look like and help with identifying the right type of person to lead the program - Brian For Brian, his pre-existing knowledge of sport psychology influenced experiences of hiring a SPC. However, for Robert it was apparent that the SPCs experience was a crucial factor in determining agreement on consultant philosophy: When they come in and have no experience and are saying, this is how we want to do it, you know, we look at it and say "what is this based on”, but with the guy we hired he had worked in [sport] and we discussed his time there and it gave them more credibility really - Robert Robert suggests that neophyte sport psychologists, who have less experience and reputation than their experienced counterparts, must be prepared to sacrifice their philosophy 
in order to gain entry. When asked for advice for SPCs attempting to gain entry to practice,

Stephen suggested:

Come with principles and you come with knowledge and experiences and you adapt your skills to solve the solution in the first place - Stephen In addition to consulting philosophy, participants indicated that candidates were

473 required to propose a plan of work they would conduct once entry had been gained.

Participants experience was characterised by the way in which consultants responded to sports, and this is what I'm going to do here based on my previous experiences. They had no lee-way in their approach and knew exactly how they wanted to do things before they had even spoken to us about the role. On the other hand, we had people that would come in and say well you tell me what to do and I'll do it. They had no impetus, it seemed to me like they didn't really know what they were doing, and that may not have been the case, but that distinct lack of direction and independence made me lose a bit of confidence in their ability to work with my players. Both styles made me and my team feel uneasy - Matt In the end we had to go for somebody that had their plan, but say woah you know let's slow down a bit and let's get on a level playing field, settle you in and then we can discuss the finer points of the role. In the end that worked well, but the actual experience, it made it difficult for us to actually choose someone, there was a point where we were thinking we were just going to leave it - Robert 
491 Matt feeling unease and Robert contemplating withdrawing from the entire process of

492

493

494

495

496

497

498

499

500

501

502

503

504

505

506

507

508

509

510

511

512

513

514

515

employing a practitioner. However, Brian proposed that SPCs should attempt to display

autonomy whilst indicating that flexibility is essential:

I want to know how they would influence the program within the parameters of what we have as an academy, I would want to know where they want to take it, if they had a little bit of autonomy, a little bit of being able to do that, and whether they could stretch me and my thought process - Brian

\section{Consultant Competency: 'Those were the things I went tick, tick, tick'}

Through extended discussions regarding the factors that led to a gatekeeper's historic decision to hire a SPC or not, participants highlighted that candidates varied in their ability to present their competencies:

It was essential that the psychologist had a good knowledge of the sport so that he could actually talk to the coaches in a way that they would listen because if you're not from a sport and you try to speak to people from the sport it’s difficult you know.

He’s a [sport] player himself so he could talk the language you know he knew what it was like, what the anxiety was like [playing the sport] he knew what the whole thing was about and um that was very telling for us - James

During discussions with James, it became apparent that sport-specific knowledge was necessary for a positive experience, however, a deeper understanding of the sport, above and beyond that of talking the talk was telling. This deeper understanding may develop from the consultant's athletic background within the same or similar sport, however an understanding is not necessarily predicated on experience within the sport.

A further competency that SPCs presented and discussed was their consulting experience. Participants diverged in the type and level of experience that they suggested to be preferential: 
516

Their experience, that was a big part, not really their overall experience as a psych, but had they worked within a similar sport to ours, to what level, with what demands and had they had any success, because if they didn't understand our sport, it would have been a struggle - Matt Our sport psychologists are working with [elite level] athletes, it's very very rare for somebody at that level to have [elite level] experience and that's the problem we have so usually and not in every case but usually the experience that people are gaining through stage two is with university level athletes or local athletes or a local club and they just do not have the exposure to this context - Sarah For Sarah the consultant's experience was characterised by the level of sport in which an individual gained experience, and whether this translated into adequate preparation for the current role. In contrast, Matt's discussion centred on the type of sport that the consultant had gained experience in.

Participants highlighted their preference for a consultant who possessed desirable characteristics such as sport-specific knowledge and particular experiences within sport psychology. However, it became apparent through further discussion concerning these characteristics that for the participants, it was the consultant's ability to present these characteristics in relation to the current role that influenced perceptions of the SPC. Stephen suggested that being able to effectively present competencies could increase gatekeepers’ confidence in the candidate:

I think there's also people that are actually quite bad at answering questions, in interviews people that answer interview questions well, when you're digging into their experiences um will quickly go to a real-life example, that tells me two things, one um that they've prepped and they've thought about the kind of things that will come up at interview and they've thought about their careers and some of the things they've 
541

542

543

544

545

546

547

548

549

550

551

552

553

554

555

556

557

558

559

560

561

562

563

564

been successful at, so it's in their short term memory, and it starts to trip off the tongue really quickly, and it's also that they know how to sell themselves, cause that's how you would operate with a coach or athlete, you'd engage in conversation with them and they'd go into examples, you'd go into scenarios and the more specific you can be the harder it is for an interview panel to argue with you so if you start talking generically or vaguely about how you would tackle something, um, you're in a game of opinions - Stephen

\section{Discussion}

Current United Kingdom gatekeepers to sport psychology were interviewed to better understand their lived experiences of hiring SPCs. The gatekeepers' experiences were interpreted to be characterised by consultant affability, consultant confidence versus arrogance, consultant collaboration, and presentation of consultant competencies. To the authors knowledge, this study provides the first qualitative account regarding the employment interview within sport psychology. These findings advance research on SPC gaining entry, and interview and impression management literature from differing disciplines by increasing our understanding of those factors idiosyncratic to the role of the SPC. By sampling from a novel population and utilising an interpretative phenomenological approach, several limitations of past research were addressed to progress the understanding of gaining entry as far as possible.

\section{The findings and interpretations presented in the current study indicate that sport} psychologists should endeavour to view the employment interview process, in the most part, as similar to that within other professional disciplines, where self-presentation, interpersonal, and impression management skills are important. In addition, features specific to the practice of sport psychology, such as their philosophy and model of practice, and interdisciplinarity, 
565 were highlighted as influential in participants' experiences. The four essences interacted to influence participants’ experiences in several ways.

All gatekeepers in this study felt that a consultant's affability played an influential

568 part on their experiences. The ability to build rapport has been reported as one of the most

569 important characteristics of an effective service provider, aiding in successful service

570 provision during the consultancy stage (Campbell, 2009; Sharpley, Jeffrey, \& McMah, 2006;

571 Orlick \& Partington, 1987). In addition, past research (Lubker et al., 2012; Woolway \&

572 Harwood, 2015) has indicated that interpersonal skills, defined as the broad "ability of the

573 consultant/practitioner to use his or her personality (e.g., approachable, respectful, caring) to

574 build a positive working relationship with athletes and coaches” (Woolway \& Harwood,

575 2015; p.173) are important to potential consumers. However, this previous definition has

576 disregarded both the gatekeeper (i.e., employer), and specific interpersonal qualities. Through

577 detailed discussions a deeper understanding emerged of the specific interpersonal qualities

578 (e.g. trust and respect) that characterised the gatekeepers' lived experiences. The descriptions

579 given by Matt, Robert, Brian, and Andrew here echo those of other potential consumers; that

580 there is a high importance placed on the ability to build rapport, trust, and respect. However,

581 it was apparent from the detailed descriptions of the gatekeepers that a further set of

582 interpersonal skills are required during the interview stage. Drawing upon the gatekeepers

583 experiences it is proposed that interpersonal skills required to interact with potential

584 employers may be different to those needed to successfully navigate a consulting relationship

585 with coaches, athletes, and parents. This may be predicated on developing a level of rapport

586 between colleagues rather than a consultant-client relationship that has been the focus of

587 previous research. This set of interpersonal skills on behalf of the SPC led participants to feel 588 a sense of wanting to hire the individual on their connection and rapport building alone. 

seeking to enter elite sport, as they are derived from the experiences of individuals that

591 influence this gaining entry process. It is advised that practitioners place significant

592 importance on learning how to establish rapport during interactions with potential

593 gatekeepers to consultancy. Additionally, echoing recent research, it would be remiss of

594 practitioner training programs if an emphasis on education and practice around rapport

595 building skills was not integrated into program content (Thelwell et al., 2018). Thelwell and

596 colleagues (2018) suggested that a rigid appraisal of interpersonal skills would be appropriate

597 for both neophyte SPCs entering qualification pathways and more experienced SPCs as a

598 feature of their continual professional development.

599 Recent research has identified the efficacy of simulation training to aid in the 600 development of interpersonal and communication skills (DeBenedectis, Gauguet, Makris,

601 Brown, \& Rosen, 2016; Rivera-Gutierrez, Lok, Kleinsmith, Childs, \& Pileggi, 2016).

602 Simulation training entails the participant encountering simulated scenarios that require the 603 skills under study, and receive feedback either in-action (Rivera-Gutierrez et al., 2016) or 604 between simulations (DeBenedectis et al., 2016). Continued practice with simulated 605 experiences can aid in the development of skills for future interactions (Rivera-Gutierrez et al., 2016). Both studies found that simulation combined with informative external feedback

607 resulted in an increased performance in communication skills (DeBenedectis et al., 2016) and 608 interpersonal skills (Rivera-Gutierrez et al., 2016).

609 For some of the participants, a perception of affability was constructed early during 610 the interview process. Fiske, Cuddy, and Glick (2007) suggest that individuals differentiate

611 others by warmth and competence dimensions in spontaneous (first) impressions. The 612 warmth dimension relates constructs including friendliness, sincerity, trustworthiness, and 613 morality. This suggests that participants perception of the SPCs affability was determined by 
614 judgements pertaining to warmth and the competence dimension related to the characteristics

615 (i.e. sport-specific knowledge and experience) the SPCs presented. Thus, the interpretations

616 of gatekeepers’ experiences may be explained by their judgements of SPC warmth and

617 competence. However, a number of additional factors (i.e. philosophy, interdisciplinarity, and

618 discipline-specific beliefs) that are idiosyncratic to the practice of applied sport psychology

619 were described by participants.

620 A further essence derived from the gatekeepers' accounts is that of the collaborative

621 nature of the consultant. The participants discussed the negative influence of consultants who

622 failed to both develop an autonomous plan and ignore the specificity of the sport and new

623 environment when designing a consultancy program. This finding was particularly pertinent

624 to the gatekeepers that had more experience of employing sport psychologists and

625 implementing their programs, as these individuals had gained an understanding and sense of

626 what they desired. This implies that a larger range of flexibility may be required when

627 preparing to consult with these gatekeepers. However, consultants should remember that

628 engaging with either extreme of such behaviour risks not gaining entry, as neither approach

629 leads to either a positive gatekeeper experience or perception of the consultant. For the

630 applied SPC, this suggests that using their own experiences to develop a programme of work

631 that can be altered slightly to the needs and wants of the organisation is crucial. This need for

632 flexibility may be particularly pertinent for the neophyte sport psychologist who intuitively

633 will have lower levels of professional experiences to build a programme around, in addition

634 to a lack of reputation and respect that may precede a more experienced consultant.

635 Participants described how a consultant possessing sport-specific knowledge, athletic

636 background, and experience was important, yet the extent to which gatekeepers reported a

637 positive interaction was determined by the consultants' ability to present these in an

638 "effective way and how they will help in the current role”. Hence, it is important for the 
639 consultant to possess the ability to promote oneself without sounding over-confident (Fifer,

640 Henschen, Gould, \& Ravizza, 2008). Self-promotion can sometimes be uncomfortable (Fifer

641 et al., 2008), but practitioners should use examples of past relevant work to present expertise

642 in the field, whilst utilising terminology of the current sport, to demonstrate an honest

643 representation of them and the field. Ravizza (1988) suggested that this sport specific

644 knowledge can "be developed through reading, taking physical education courses, talking

645 with people who play the sport” (p.247), viewing the game, and playing the sport itself.

646 Similarly, Brown, Gould, and Foster (2005) suggested that "learning the language” (p.55) of

647 the sport is a key factor of contextual intelligence. Contextual intelligence refers to an

648 understanding of the culture and context which is being operated in and is required in

649 addition to knowledge of techniques and strategies to build legitimacy, trust and respect

650 (Winter \& Collins, 2015). A practitioner can learn the language by “visiting and immersing

651 oneself in the culture... attend practices and travel with the team. One may want to shadow

652 the team trainer” (Brown et al., 2005, p.56)

653 Participants' perceptions of consultants were further characterised by a consultant's

654 confident or arrogant attitude regarding sport psychology. When describing a consultant who 655 was perceived to be arrogant, participants highlighted that exaggerating the potential impact 656 that sport psychology could have led to negative perceptions, affect, and withdrawal from the 657 interaction. The ability to self-promote without this hyperbole is deemed to have a positive 658 impact on participants’ perceptions of the consultant and the sport psychologist's likelihood 659 to gain entry. The over-selling of sport psychology has been a concern echoed in several 660 applied practitioner’s recounts of experience within previous research studies (Fifer et al., 661 2008; Ravizza, 1988). Hemmings and Holder (2009) suggest that it is commonplace for 662 consumers to believe sport psychology to be a 'quick fix' solution in competitive sport, and 663 the resulting pressure can lead to a long-term perspective being sacrificed (Ravizza, 1988). 
664 This pressure can lead sport psychology practitioners to agree with gatekeepers regarding time frames; however, the results of quick fix programs are often suspended before being able to make a significant impact (Ravizza, 1988). This early suspension of services can make it harder for other practitioners to gain entry in the future, and can discredit the profession. Sport psychology practitioners should be honest with the gatekeeper about any

669 limitations and the need for long-term commitment (Ravizza, 1988), and should adopt a subtle low-key approach using examples to present expertise within the field (Fifer et al.,

671 2008).

The gatekeepers' discussions reinforced previous suggestions that consultants should

673 recognise that they are part of an interdisciplinary team contending with a number of

674 performance issues and should complement their colleagues (Fifer et al., 2008; Halliwell,

675 Orlick, Ravizza, \& Rotella, 2003). As Fifer and colleagues (2008) suggest, sport psychologists may sometimes forget that other professionals have performed successfully

677 without their expertise. Thus, practitioners should understand and appreciate the place of 678 sport psychology in relation to other professions, and demonstrate their ability to work as part 679 of an interdisciplinary team with appropriately illustrative examples of previous work in such 680 contexts.

681 The findings of the current study support research from wider psychological literature 682 regarding the employment interview. The skills highlighted by gatekeepers align with the 683 social effectiveness skills suggested to be a major source construct of interviewer ratings 684 (Huffcutt, 2011). These social effectiveness skills, described as "the notion that candidates 685 really put on a performance” (Huffcutt, 2011; p. 74) include social influence behaviors and 686 interpersonal presentation that directly influence interview ratings. In addition, impression 687 management tactics utilised can be altered and manipulated to best suit the situation in which 688 they are required (Peeters \& Lievens, 2006). The current findings extend this understanding 
689 of impression management and interpersonal skills to the sport psychology domain.

690 Practitioners may need to develop a new set of social effectiveness skills to effectively

691 interact with potential employing agents. In addition to supporting Huffcutt's (2011) model

692 of major sources of interview ratings, the current findings extend this collection of constructs

693 to include items specific to the field of applied sport psychology. These are the SPC's

694 philosophy, their attitude toward interdisciplinarity, and their discipline specific beliefs.

695 Within the United Kingdom, both the British Psychological Society (BPS) candidate

696 handbook for the Qualification in Sport and Exercise Psychology (Stage2) (BPS, 2018) and

697 the British Association of Sport and Exercise Sciences (BASES) Supervised Experience

698 Competency Profile (BASES, 2016) highlight the need to establish, mediate, develop, and

699 maintain working relationships. Cotterill (2016) argued that these programs are often lacking

700 the practical business skills that are necessary to succeed as a SPC. This is supported by

701 neither of the BPS or BASES document referring to interviewing skills and the techniques to

702 communicate one's philosophy, or the training of these abilities. The findings of this study

703 highlight this apparent gap within training programmes of SPCs which may result in

704 neophyte practitioners lacking the basic professional skills they require to succeed.

705 Professional competencies is an issue that sport psychology is still facing as a relatively new,

706 developing profession, with training documentation often providing insufficient preparation

707 for trainees (Fletcher \& Maher, 2013; Portenga, Aoyagi, \& Cohen, 2017). Developing these

708 competencies to produce an adequate pool of appropriately trained professionals is required

709 for the health and development of the profession (Portenga et al., 2017; Winter \& Collins,

710 2016). Hence, these findings should act as valuable considerations for both the trainee SPC

711 and the governing bodies that are responsible for educating and regulating the profession.

712 The current study enhanced understanding of the sport psychologist's employment

713 interview. However, we acknowledge some limitations when interpreting these findings. 
714 First, the sample were solely from the United Kingdom, and gatekeeper experience may differ depending on the nationality of the individual and the country in which they are working. This difference may occur due to the differing structure of organisations and

717 perceptions towards sport psychology that may exist. Similarly, the sample all held roles in 718 elite sport organisations; an environment where an employment interview may be more likely 719 than lower competitive levels of sports organisations.

\section{Future Directions}

The findings of this study provide a rich and detailed phenomenological support for

722 an often quantitatively focused area of study, that has relied on questionnaires and surveys

723 (e.g. Lubker et al., 2008; Woolway \& Harwood, 2015), additionally seeking the experiences

724 of a novel sample. These high-performance gatekeepers have informed the processes that are important for SPCs working in elite settings to consider where there are distinct opportunities for employment. In light of this future research should aim to develop and assess the efficacy

727 of a training program for enhancing the entry interview skills of SPCs. It is important to take 728 note of recent research within allied professions (DeBenedectis et al., 2016; Rivera-Gutierrez 729 et al., 2016) that have demonstrated the effectiveness of simulated training coupled with either in-action or between scenario feedback on communication and interpersonal skills. Sport psychology research should endeavour to assess similar forms of training to aid in the development of current and future SPCs.

An additional future direction for this line of research relates to the suggestions of the gatekeepers in the current study. They emphasized that neophyte sport psychologists may need to make sacrifices regarding their philosophy and may find it harder to present their limited experiences. Hence, it is important for the development of future sport psychologists

737 that we assess whether trainee and neophyte sport psychology consultants: a) are aware of 738 these essences, b) possess these skills, and c) receive appropriate training in these areas. 
739

740

741

742

743

744

745

746

747

748

749

750

751

752

753

754

755

756

757

758

759

760

761

762

763

\section{References}

Allen-Collinson, J. (2009). Sporting embodiment: Sports studies and the (continuing) promise of phenomenology. Qualitative Research in Sport and Exercise, 1, 279-296, doi: 10.1080/19398440903192340.

Andersen, M.B. (2000). Beginnings: Intakes and the initiation of relationships. In M.B. Andersen (Ed.), Doing sport psychology (pp. xiii-xvii). Champaign, IL: Human Kinetics.

Anderson, A., Miles, A., Robinson, P., \& Mahoney, C. (2004). Evaluating the athlete’s perception of the sport psychologist's effectiveness: What should we be assessing? Psychology of Sport and Exercise, 5, 255-277, doi: 10.1016/S1469-0292(03)00005-0.

Arvinen-Barrow, M., Penny, G., Hemmings, B., \& Corr, S., (2010). UK chartered physiotherapists’ personal experiences in using psychological interventions with injured athletes: an interpretative phenomenological analysis. Psychology of Sport and Exercise, 11, 58-66.

British Association of Sport and Exercise Sciences. (2016). Supervised experience competency profile. Retrieved from http://www.bases.org.uk/SE-ApplicationDocuments-and-Guidelines

British Psychological Society. (2018). Qualification in sport and exercise psychology (stage 2): Candidate handbook [PDF]. Retrieved from https://www.bps.org.uk/sites/beta.bps.org.uk/files/Qualifications/QSEP\%20\%28Stage \%202\%29\%20Candidate\%20Handbook\%20Jan\%202018.pdf

Brocki, J. J. M., \& Wearden, A. J. (2006). A critical evaluation of the use of interpretative phenomenological analysis (IPA) in health psychology. Psychology and Health, 21, 87-108.

Brown, C. H., Gould, D., \& Foster, S. (2005). A framework for developing contextual 

intelligence (CI). The Sport Psychologist, 19, 51-62.

765

766

767

768

769

770

771

772

773

774

775

776

777

778

779

780

781

782

783

784

785

786

787

788

Campbell, K. (2009). Physicians and patients: How professionals build relationships through rapport management. In G. F. Hayhoe \& H. M. Grady (Eds.), Connecting people with technology: Issues in professional communication, (pp145154). Amityville, NY: Baywood Publishing Co.

Caron, J. G., Bloom, G. A., Johnston, K. M., \& Sabiston, C. M. (2013). Effects of multiple concussions on retired National Hockey League players. Journal of Sport and Exercise Psychology, 35, 168-179.

Clarke, N. J., \& Harwood, C. G. (2014). Parenting experience in elite youth football: A phenomenological study. Psychology of Sport and Exericse, 15, 528-537.

Cotterill, S. (2016, September 5). What should we be teaching trainee sport, exercise and performance psychologists? Retrieved from https://stewartcotterill.co.uk/2016/09/05/what-should-we-be-teaching-trainee-sportexercise-and-performance-psychologists/

Coumbe-Lilley, J. (2011). Failed contracting: Lessons learned from false starts with national, state, and local sport organizations. Journal of Sport Psychology in Action, 2, 131-142. doi: 10.1080/21520704.2011.597495

Crotty, M. (1998). The Foundations of Social Research. Thousand Oaks, CA: Sage.

DeBenedectis, C. M., Gauget, J., Makris, J., Brown, S. D., \& Rosen, M. P. (2016). Coming out of the dark: A curriculum for teaching and evaluating radiology residents’ communication skills through simulation. Journal of the American College of Radiology, 14, 87-91.

Dorn, F. J. (1984). The social influence model: A social psychological approach to counseling. Personnel \& Guidance Journal, 62, 342-345. doi.org/10.1111/j.21644918.1984.tb00221.x 
789 Fifer, A., Henschen, K., Gould, D., \& Ravizza, K. (2008). What works when working with athletes. The Sport Psychologist, 22, 356-377.

791 Fiske, S. T., Cuddy, A. J. C., \& Glick, P. (2007). Universal dimensions of social cognition: Warmth and competence, Trends in Cognitive Sciences, 11 (2), 77-83.

793 Fletcher, D., \& Maher, J. (2013). Toward a competency-based understanding of the training and development of applied sport psychologists. Sport, Exercise and Performance Psychology, 2, 265-280.

796

Giorgi, A. (2011). IPA and science: a response to Jonathan Smith. Journal of Phenomenological Psychology, 42, 195-216.

Gould, D., Murphy, S., Tammen, V., \& May, J. (1991). An evaluation of U.S. Olympic sport psychology consultant effectiveness. The Sport Psychologist, 5, 111-127.

800

Guest, D. (1998). Is the psychological contract worth taking seriously? Journal of

801 Organizational Behavior, 19, 649-664.

802 Halliwell, W., Orlick, T., Ravizza, K., \& Rotella, B. (2003). Consultant’s guide to 803 excellence. Chelsea, PQ: Terry Orlick.

804 Hamill, R., Carson, S., \& Dorahy, M., (2010). Experiences of psychosocial 805 adjustment within 18 months of amputation: an interpretative 806 phenomenological analysis. Disability and rehabilitation, 32, 729-740.

807 Hash, R. B., Munna, R. K., Vogel, R. L., \& Bason, J. J. (2003). Does physician 808 809 weight affect perception of health advice? Preventive Medicine, 36, 41-44. doi:10.1006/pmed.2002.1124

810 Hays, K., Maynard, I., Thomas, O., \& Bawden, M. (2007). Sources and types of confidence identified by world class sport performers. Journal of Applied Sport Psychology, 19, 434-456.

813 Hemmings, B., \& Holder, T. (2009). Applied sport psychology: A case-based 
814

841

842

843

844

845

846

847

848

849

850

851

852

853

854

855

856

857

858

859

860

861

862

863

864

approach, Chichester, UK. Wiley-Blackwell

Higgins, C. A., \& Judge, T. A. (2004). The effect of applicant influence tactics on recruiter perceptions of fit and hiring recommendations: A field study. Journal of Applied Psychology, 89, 622-632.

Hodge, K. (2010). Working at the Olympics. In S. J. Hanrahan, \& M. B. Andersen (Eds.), Routledge handbook of applied sport psychology (pp. 405-413). London: Routledge.

Huffcutt, A. I. (2011). An empirical review of the employment interview construct literature. International Journal of Selection and Assessment, 19, 62-81.

Humara, M. (2000). Personnel selection in athletic programs. Athletic insight, 2. Retrieved from www.athleticinsight.com/Vol2Iss2/Personnel.htm

Husserl, E. (1973). Experience and judgement. London: Routledge.

Johnson, U., Andersson, K., \& J. Fallby. (2011). Sport psychology consulting among Swedish premier soccer coaches. International Journal of Sport and Exercise Psychology, 9(4), 308-322, doi: 10.1080/1612197X.2011.623455

Larkin, M., Watts, S., \& Clifton, E. (2006). Giving voice and making sense in interpretative phenomenological analysis. Qualitative Research in Psychology, 3, 102-120.

LeCompte, M. D., \& Schensul, J. J. (1999). Designing and conducting ethnographic research, Walnut Creek, CA: Alta Mira Press.

Lewis, K. N., \& Walsh, W. B. (1978). Physical attractiveness: Its impact on the perception of a female counselor. Journal of Counseling Psychology, 25, 210-216. doi.org/10.1037/0022-0167.25.3.210

Lubker, J. R., Visek, A. J., Geer, J. R., \& Watson II, J. C. (2008). Characteristics of an effective sport psychology consultant: Perspectives from athletes and consultants. Journal of Sport Behavior, 31, 147-165. 
865

866

867

868

869

870

871

872

873

874

875

876

877

878

879

880

881

882

883

884

885

886

887

888

889

Lubker, J. R., Visek, A. J., Watson, J. C., \& Singpurwalla, D. (2012). Athletes’ preferred characteristics and qualifications of sport psychology practitioners: A consumer market analysis. Journal of Applied Sport Psychology, 24, 465-480. doi.org/10.1080/10413200.2012.694968

Lukacs, J.D. (2010, June). Programs decades in the making. Retrieved from http://sports. espn.go.com/ncf/news/story?id=5312405/

Miller, P. K., Cronin, C., \& Baker, G. (2015). Nurture, nature and some very dubious social skills: An interpretative phenomenological analysis of talent identification practices in elite English youth soccer. Qualitative Research in Sport, Exercise and Health, 7, 642-662.

Orlick, T., \& Partington, J. (1987). The sport psychology consultant: Analysis of critical components as viewed by Canadian Olympic athletes. The Sport Psychologist, 1, 4-17.

Pain, M.A., \& Harwood, C.G. (2004). Knowledge and perceptions of sport psychology within English soccer. Journal of Sports Sciences, 22, 813-826. doi.org/10.1080/02640410410001716670

Peeters, H., \& Lievens, F. (2006). Verbal and nonverbal impression management tactics in behaviour description and situational interviews. International Journal of Selection and Assessment, 14, 206-222.

Poczwardowski, A., Sherman, C. P., \& Henschen, K. P. (1998). A sport psychology service delivery heuristic: Building on theory and practice. The Sport Psychologist, 12, 191207.

Poczwardowski, A., Sherman, C.P., \& Ravizza, K. (2004). Professional philosophy in the sport psychology service delivery: Building on theory and practice. The Sport Psychologist, 18, 445-463. 
890 Portenga, S. T., Aoyagi, M. W., \& Cohen, A. B. (2017). Helping to build a profession: A 891 working definition of sport and performance psychology. Journal of Sport Psychology in Action, 8, 47-59.

Ravizza, K. (1988). Gaining entry with athletic personnel for season-long consulting. The Sport Psychologist, 2, 243-254.

Reid, K., Flowers, P. and Larkin, M. (2005). Exploring lived experience: an introduction to 896 interpretative phenomenological analysis. Psychologist, 18, 20-23.

Rhodes, J. \& Smith, J.A., (2010). “The top of my head came off”: an interpretative phenomenological analysis of the experience of depression. Counselling psychology quarterly, 23, 399-409.

900 Rivera-Gutierrez, D., Lok, B., Kleinsmith, A., Childs, G., \& Pileggi, R. (2016). Self901 assessment through interactive in-action reflections to improve interpersonal skills training. In J. M. Spector, C-C. Tsai, D. G. Sampson, Kinshuk, R. Huang, N-S, Chen, 906 \& P. Resta (Eds.) Proceedings of Advanced Technologies for Supporting Open Access

Sanders, P., \& Winter, S. (2016). Going pro: Exploring adult triathletes’ transitions into elite 908 909 sport. Sport, Exercise, and Performance Psychology, 5, 193-205, doi:10.1037/spy0000058.

910 Sands, R. R. (2002). Sport ethnography, Champaign, IL: Human Kinetics.

911 Sharp, L., \& Hodge, K. (2011). Sport psychology consulting effectiveness: The sport psychology consultant’s perspective. Journal of Applied Sport Psychology, 3, 360376.

914 Sharp, L. \& Hodge, K. (2014). Sport psychology consulting effectiveness: The athlete’s 
915

916

917

918

919

920

921

922

923

924

925

926

927

928

929

930

931

932

933

934

935

936

937

938

939

perspective, International Journal of Sport and Exercise Psychology, 12, 91-105, doi: 10.1080/1612197X.2013.804285

Sharpley, C. F., Jeffrey, A. M., \& McMah, T. (2006). Counsellor facial expression and client-perceived rapport, Counselling Psychology Quarterly, 19, 343-356.

Smith, B. \& McGannon, K. R. (2017). Developing rigor in qualitative research: problems and opportunities within sport and exercise psychology, International Review of Sport and Exercise and Psychology, DOI: 10.1080/1750984X.2017.1317357.

Smith, J. A. (2016). Interpretative phenomenological analysis in sport and exercise:

Getting at experience. In B. Smith \& A. C. Sparkes (Eds.), Routledge handbook of qualitative research in sport and exercise (pp.219-229). Abingdon, Ox: Routledge.

Smith, J.A., Flowers, P. \& Larkin, M. (2009). Interpretative phenomenological analysis: theory, method and research. London: Sage.

Smith, J.A. \& Osborn, M. (2004). Interpretative phenomenological analysis. In G.M. Breakwell (Ed.), Doing social psychology research (pp.229-254). Oxford: BPS Blackwell.

Sport England (2015). Benefits of sport. Retrieved from https://www.sportengland. org/research/benefits-of-sport/

Tamminen, K. A., Holt, N. L., \& Neely, K. C. (2013). Exploring adversity and the potential for growth among elite female athletes. Psychology of Sport and Exercise, 14, 28-36, doi: 10.1016/j.psychsport.2012.07.002.

Thelwell, R. C., Wood, J., Harwood, C., Woolway, T., \& van Raalte, J. L. (2018). The role, benefits and selection of sport psychology consultants: Perceptions of youth-sport coaches and parents, Psychology of Sport and Exercise, 35, 131-142.

Vachon, M., Fillion, L., Achille, M., Duval, S., \& Leung, D. (2011). An awakening experience: An interpretative phenomenological analysis of the effects of a 

meaning-centered intervention shared among palliative care nurses. Qualitative research in psychology, 8, 66-80.

942 Wilson, K.A., Gilbert, J. N., Gilbert, W. D., \& Sailor, S. R. (2009). College athletic 943 directors' perceptions of sport psychology consulting. The Sport Psychologist, 23, 405-424. Doi.pdf/10.1123/tsp.23.3.405

945 Winter, S., \& Collins, D. (2015). Why do we do, what we do? Journal of Applied Sport 946 Psychology, 27, 35-51.

947 Winter, S., \& Collins, D. (2016). Applied sport psychology: A profession? The Sport 948 Psychologist, 30, 89-96.

949 Woolway, T. \& Harwood, C. G. (2015). Do title matter in sport psychology?

950 Performer attitudes toward professional titles and the effect of a brief intervention. The Sport Psychologist, 29, 171-182.

952 Wrisberg, C., Withycombe, J. L., Simpson, D., Loberg, L. A., \& Reed, A. (2012). NCAA division-1 administrators' perceptions of the benefits of sport 954 psychology services and possible roles for a consultant. The Sport Psychologist, 26, 16-28. 